\title{
Superplume Project: Towards a new view of whole Earth dynamics
}

\author{
Mizuho Ishida ${ }^{1}$, Shigenori Maruyama ${ }^{2}$, Daisuke Suetsugu $^{3}$, Shigeru Matsuzaka ${ }^{4}$, and Takao Eguchi ${ }^{1}$ \\ ${ }^{1}$ Solid Earth Science Division, National Research Institute for Earth Science and Disaster Prevention, \\ Tennodai 3-1, Tsukuba, Ibaraki 305-0006, Japan \\ ${ }^{2}$ Department of Earth and Planetary Sciences, Tokyo Institute of Technology, Oh-okayama 2-12-1, Meguro-ku, Tokyo 152-0033, Japan \\ ${ }^{3}$ International Institute of Seismology and Earthquake Engineering, Building Research Institute, Tatehara 1, Tsukuba, Ibaraki 305-0802, Japan \\ ${ }^{4}$ Geography and Crustal Dynamics Research Center, Geographical Survey Institute, Hokugo 1, Tsukuba, Ibaraki 305-0811, Japan
}

(Received July 27, 1998; Revised October 26, 1998; Accepted November 7, 1998)

According to the theory of plate tectonics proposed in the late 1960's, the Earth's surface is covered by about ten rigid plates, which are generated at mid-oceanic ridges, move to oceanic trenches, and there subduct into the mantle. A theory of plate tectonics explains most geologic phenomena such as seismicity, volcanism, and magnetic striping of the ocean-floor. However, the theory of plate tectonics explains only the orogenic phenomena occurring in the uppermost several hundred of kilometers of the Earth's interior. It is, therefore, a theory covering less than 1/10 of the Earth's diameter (left in Fig. 1).

During the 1980's studies of seismic tomography provided a new view of the Earth's interior, and hence our understanding of the Earth's dynamics has considerably improved. Beneath the southern Pacific a large-scale lowvelocity region is present (e.g., Inoue et al., 1990), whereas beneath Asia a higher velocity region is present. The former region is characterized by a topographic high exceeding $1000 \mathrm{~m}$ (e.g., Crough, 1983) and also by several hot spots, suggesting the presence of large-scale mantle upwelling. The latter region corresponds to the area in which the largest amount of oceanic lithosphere has subducted during the last $300 \mathrm{Ma}$, suggesting the presence of mantle downwelling in central Asia (middle in Fig. 1).

Maruyama (1994) and Maruyama et al. (1994) proposed "Plume tectonics" to explain not only the superficial layer but also dynamics in the whole Earth: Subducted slabs in the western Pacific are stagnant at the $670 \mathrm{~km}$ discontinuity because of the endothermic phase transition and eventually collapse to form a cold mantle downwelling to the core mantle boundary (CMB). Two large-scale mantle upwellings are present in the lower mantle under the south Pacific and Africa (hot superplume). The whole-mantle scale convection controlled by the large-scale flow is called plume tectonics and should play a major role in the Earth's dynamics. The material circulation of the superplumes should carry not only heat but also incompatible elements in each layer, which should be identifiable in the chemical signature of hotspot magma (right in Fig. 1).

The Superplume Project, funded by Japan's Science and Technology Agency, started in 1996 to examine the above working hypothesis and establish a new view of whole Earth dynamics. The project is interdisciplinary and involves a broad range of Earth sciences: seismology, geology, ultra-high-pressure experiments, geodesy, and numerical simulation of mantle convection as described in detail below.

\section{Seismology}

The three-dimensional seismic velocity structure of the Earth's interior provides important information for understanding the Earth's dynamics. In recent years, many seismologists have presented 3-D Earth models based on tomographic analyses, and have discussed the implications of these models for geodynamics (e.g., Inoue et al., 1990; Su et al., 1994). Two large-scale low-velocity regions are found in the lowermost mantle underneath the South Pacific Ocean and Africa, which may be attributed to hot superplumes. However, in the tomographic images it is difficult to trace the slow velocity rising from the CMB up to hotspots at the surface, and it is still possible that the hotspots have their origin somewhere else in the mantle. The ambiguity arises mainly due to poor resolution in seismic tomography in the South Pacific and Africa, because there are not enough

Copy right (c) The Society of Geomagnetism and Earth, Planetary and Space Sciences (SGEPSS); The Seismological Society of Japan; The Volcanological Society of Japan; The Geodetic Society of Japan; The Japanese Society for Planetary Sciences. seismic stations and earthquakes in these regions. Upper mantle structure beneath the western Pacific region is characterized by high velocity zones associated with descending cold slabs, some of which form a megalith at the $670 \mathrm{~km}$ discontinuity and further penetrate into the lower mantle. The bottom of the mantle beneath the circum-Pacific region has fast velocity, which might be a relic of the cold slabs. This picture is better resolved by tomographic inversion than the South Pacific, though we still have no definitive answer as to how deep the descending slabs reach in the lower mantle. We believe that more detailed and accurate knowledge of the 3-D structure in and around the Pacific should play a key role in improving our understanding of whole Earth dynamics. The present research plan includes a five-year (at least) program of seismological observations and analyses focused on the South Pacific and the western Pacific subduction zone. We deploy the following three seismological networks: SPANET, JISNET, and GARNET. (The three networks SPANET, JISNET and GARNET, are collectively 


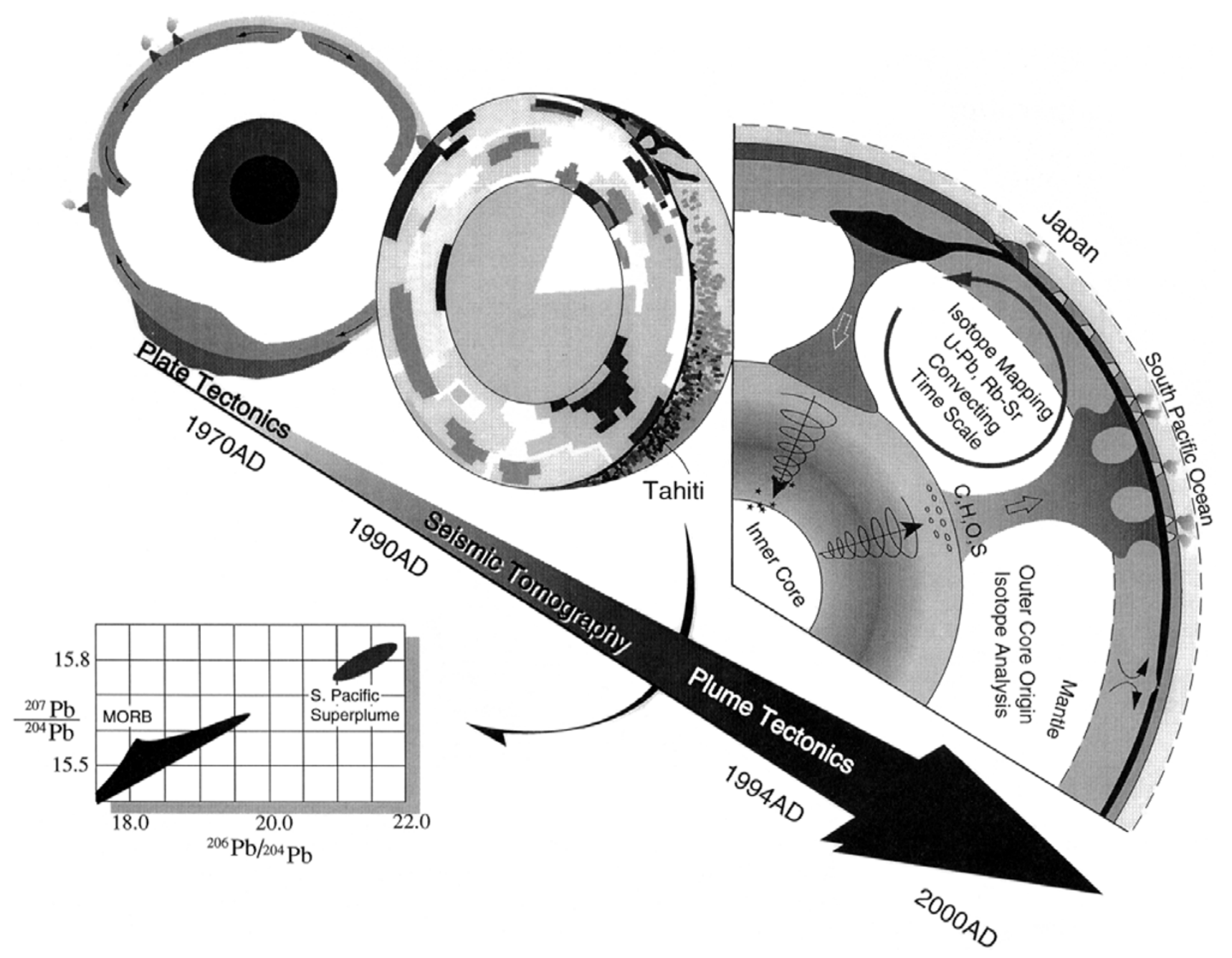

Fig. 1. Towards a new paradigm of Earth science. Our understanding of Earth structure and dynamics has advanced from plate tectonics in the 1960's (left) to a three-dimensional image obtained by seismic tomography in the 1980's \& 90's (middle). It is now time to construct an integrated understanding of Earth's dynamics via an interdisciplinary approach to Earth sciences (right).

called PANSY: PAcific Networks for SeismologY). The details of each network are as follows:

SPANET (South PAcific broadband seismic NETwork): We are deploying sixteen broad-band seismographic stations, of which ten stations are constructed under Japan-IRIS collaboration, on oceanic islands in the Central and South Pacific (From Midway in the north to Kermadec in the south, from Pitcairn in the east to Tarawa in the west). A major target of SPANET is mantle structure beneath the South Pacific where a large-scale hot plume might ascend from CMB.

JISNET (Japan-Indonesia Seismic NETwork): A broadband digital seismographic network made up of 23 temporary stations deployed in Indonesia under Japan-Indonesia collaboration. Each station is equipped with a Guralp CMG3T. The main objectives of this cooperative research are to investigate transition zone structure beneath the Indonesian subduction zone and detailed structure inside the descending Indonesian slab, and to clarify the fate of slabs from around the 670 discontinuity down to the CMB beneath the western Pacific.

GARNET (Global Alliance of Regional NETworks): Col- laborating with ten Asian and circum-Pacific countries, we make optimal use of existing resources of regional seismic networks for global seismology. Each country has a dense seismic network, but operates it only for monitoring local and regional seismicity. Teleseismic events are detected by the network but never archived, and are usually discarded without analysis. We have developed and installed a PC-based digital data acquisition system at existing regional seismic networks (mostly equipped with short-period seismographs) for teleseismic recording. A high-density international seismic network organized by GARNET enables us to perform array processing to obtain a fine image of topography of mantle discontinuities, which should clarify the interaction of mantle convection with mantle discontinuities. This is a cooperative research project with ISOP (the International Seismological Observing Period).

We need to analyze new data using advanced methodology in order to achieve high resolution of the Earth's 3-D structure. We apply a waveform inversion technique based on the DSM (Direct Solution Method) (Geller and Hara, 1993) to surface wave data for determining the 3-D upper mantle 


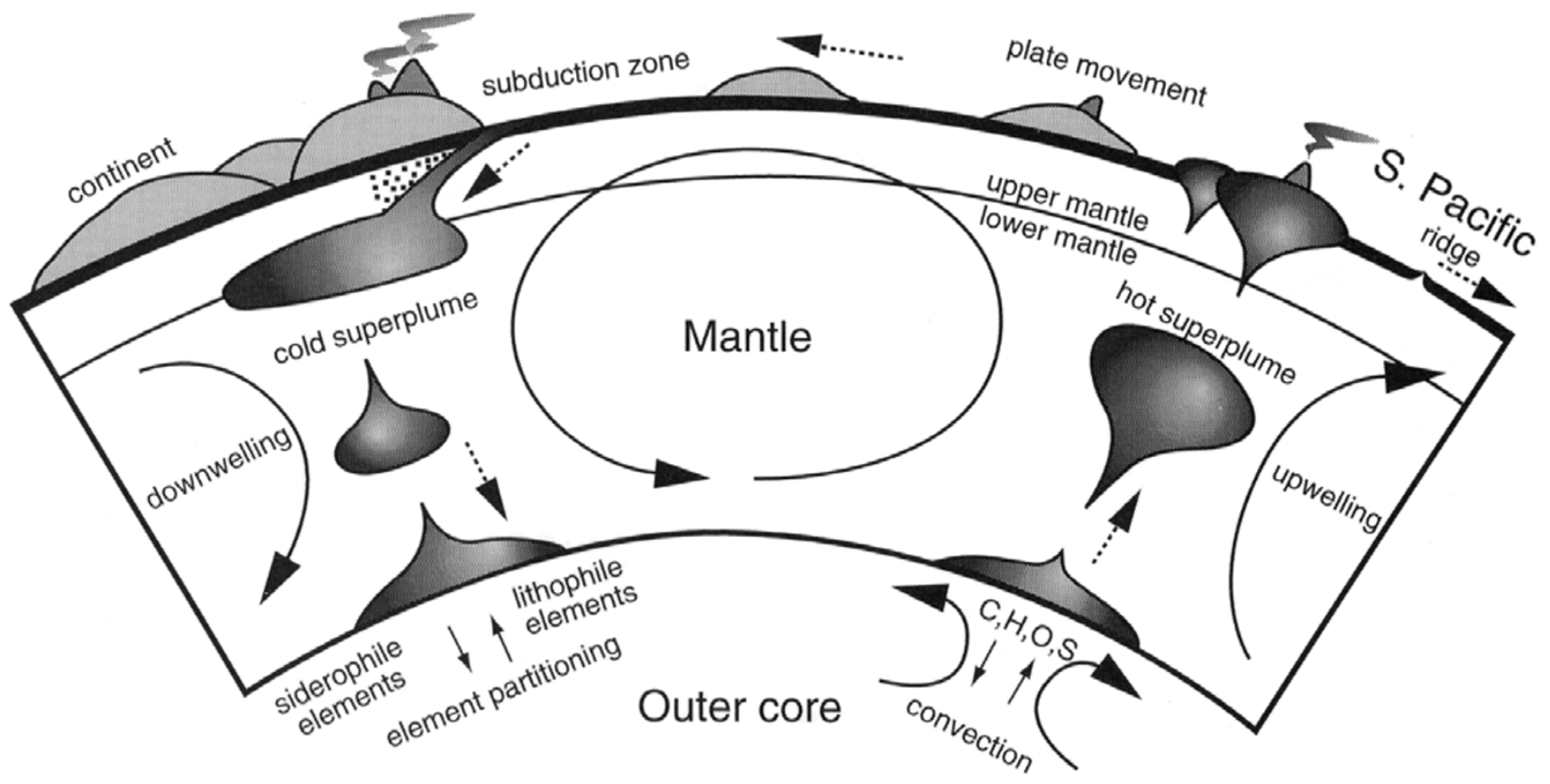

Fig. 2. Hypothesis on global material circulation in the Earth's interior. The oceanic lithosphere born at mid-oceanic ridge subducts into deeper mantle at trench, stagnates at mantle transition depth, avalanches into the bottom of the mantle finally. Chemical differentiation at mid-oceanic ridge, trench, $660 \mathrm{~km}$ depth and mantle-core boundary occurs through the global material circulation. The superplume originates at mantle/core boundary and carries light materials such as $\mathrm{C}, \mathrm{H}, \mathrm{O}$, and $\mathrm{S}$ from the outer core to the surface. The episodic activity of superplume may be related to the episodic formation and collapse of the stagnant slabs at $660 \mathrm{~km}$ depth.

structure of $\mathrm{P}$ - and S-velocities and Q to investigate thermal anomalies associated with hot spots in the South Pacific. The lowermost mantle is studied using DSM waveform inversion of diffracted waves for $V_{\mathrm{p}} / V_{\mathrm{s}}$ ratio, to assess the possibly of partial melting in D" layer. Delay time tomography is also performed for determining whole mantle P- and S-velocity structure, using not only $\mathrm{P}$ and $\mathrm{S}$-arrival times but also those of all available later phases. We will investigate topography of mantle discontinuities with receiver function analysis, taking into account lateral variations in velocity. We are going to establish a PANSY data center at NIED/STA (Tsukuba, Japan) in 1998. The SPANET and SPANET/IRIS data will be available at the data center and at the IRIS DMC, respectively. The JISNET data will be made publicly available after preliminary analyses are completed. The GARNET data will be shared in the form of CD-ROM's distributed among contributing regional seismic networks and researchers.

\section{Geology, Petrology and Geochemistry of Present and Past Superplume Rocks}

2.1 Hypothesis on global material circulation in the whole mantle scale

Since the tomographic images of whole mantle became available, the material circulation in the whole mantle has long been discussed in the light of results from multi- and diamond-anvil ultra-high pressure experiments, isotope geochemistry, numerical simulation, and plate tectonic history back for the last $150 \mathrm{Ma}$ (Hofmann and White, 1982; Maruyama et al., 1994). The most probable working hypothesis is reproduced in Fig. 2. The mantle is bounded by two boundary layers: surface lithosphere on the top and D" on the bottom. Another boundary layer may exist in the upper mantle-lower mantle boundary. Mantle convection or mantle plume must interact with these boundary layers and their shapes may be modified as shown in Fig. 2. Simultaneously, the chemical differentiation will proceed when they pass the boundary layers. First, the uprising mantle partially melts to form basalt: mid-oceanic ridge basalt (MORB) or oceanic island basalt (OIB), and restite (harzburgite). The oceanic lithosphere formed at mid-oceanic ridge is hydrated by the hydrothermal fluid circulation at spreading ridge, moves trench-wards, and subducts in the trench. The downgoing lithosphere is dehydrated to liberate fluids with considerable amounts of incompatible elements such as large-ion lithophile elements (LILE) and High Field Strength elements (HFSE) and metasomatize the mantle wedge, promoting chemical differentiation within the surface boundary layer above in the deep trench. The subducted slab partially melts if it is younger than $25 \mathrm{Ma}$, but not if it is older than 25 Ma (Defant and Drummond, 1990; Maruyama, 1997). The altered subducted lithosphere sinks to be stagnant at mantle transition depth above $660 \mathrm{~km}$. A huge melange (megalith) of the stagnant slab would finally gravitationally collapse down to CMB when it becomes as thick as $300 \mathrm{~km}$ or more. The associated geochemical differentiation may be present, but the details have not yet been clarified. The subducted oceanic crust after the chemical modification of mantle metasomatism may be finally swallowed into lower mantle together with the megaliths. Once the megaliths reach to $\mathrm{CMB}$, they refrigerate the top surface of molten outer core and a chemical reaction would take place so that siderophile elements in mantle should be replaced by the lithophile and 
light elements such as $\mathrm{C}, \mathrm{H}, \mathrm{O}$ and $\mathrm{S}$ in the core. Since the solidus temperature of the altered MORB crust in the megaliths is about $4000 \mathrm{~K}$ (Hirose et al., 1998), it may be partially melted to accelerate the chemical differentiation within the megalith on CMB. As the megaliths are heated up and chemically fractionated to form a layered structure, the upper buoyant layer would turn into superplume again (Fig. 2). To solve the detailed mechanism of chemical differentiation at boundary layers, the multi-anvil and diamond-anvil ultrahigh pressure experiments are planned, combined with numerical simulations of mantle convection and/or superplume.

\subsection{OIBs in the Pacific domain}

The Pacific superplume characterized by low-velocity tomographic images in the whole mantle scale (e.g., Inoue et al., 1990), the topographic anomaly higher than the surrounding ocean-floor (Crough, 1983; McNutt and Fisher, 1987), concentrated several hot-spots above, and anomalous isotopic signatures, all suggest the deep mantle origin of the superplume. In order to understand the origin of the superplume source, probably in the deep mantle, the detailed geochemical and chronological studies for the present Pacific Superplume lavas are being conducted. We will establish geochemical and isotopic criteria to discriminate superplume rocks.

\subsection{Past OIBs accreted in the circum-Pacific orogenic belts back to $600 \mathrm{Ma}$}

Ancient activity of the South Pacific Superplume may be documented by analyzing greenstones which have been formed by the Pacific Superplume, migrated to circumPacific subduction zones and accreted into the subduction zone complex. Detailed field mapping from the standpoint of accretionary geology, microfossil and isotopic chronology, and petrochemical works would clarify their ages and origins (whether MORB or OIB). We will adopt the newly established geochemical and isotopic criteria to identify the superplume origin.

\subsection{Development of isotope microscope}

A difficulty in analyzing the accreted greenstones that are probably of superplume origin is that those old basaltic rocks are metamorphosed when trapped in the subduction zone. The original magmatic characteristics may not be preserved in major and trace element geochemistry, and isotopic. In order to examine isotope and trace element signatures of ancient altered and/or metamorphosed superplume lavas, the isotope and trace element analyses of relic igneous minerals, such as Ca-rich clinopyroxene, amphibole, and spinel, are required. For this purpose, an isotope microscope, a secondary ionization mass spectrometer (SIMS) with ultra-high sensitivity and resolution, is newly developed in this Superplume Project. Using the improved SIMS of CMECA 1270, the detailed activity history of Pacific Superplume back to 600 $700 \mathrm{Ma}$ will be compared to the history of global change of the surface environment and large-scale material circulation on and within the Earth.

\section{Geodesy}

We deploy a GPS network in the central and South Pacific, which is the presumed area of the superplume. At the end of March 1998, three stations (Christmas Island in Republic of Kiribati, Tongatapu Island in Kingdom of Tonga, and
Rarotonga Island in Cook Islands) are operating and two more will be operational in 1999. Horizontal and vertical movements of the positions of GPS stations are expected, in which vertical changes are smaller in magnitude and more difficult to separate from the variations due to environmental and radio wave receiving conditions. Using network adjustment, i.e. observing for longer periods and averaging over the network on a global scale with additional IGS (International GPS Service) and WING (Western Pacific Integrated Network of GPS) data, we will determine the horizontal and vertical rates of GPS positional changes. Based on these observations, we would detect intraplate deformation, which might be related to activity of the plume head under the oceanic lithosphere.

There are large-scale oceanic plateaus, mountains and swells related to the superplume activity in the past and at the present. The spatial and time distribution of these topographic elements is a key to solve the history of superplume activity. Their morphological characteristics indicate the effects of the superplume on the Earth's surface. Although high resolution bathymetric data are sparsely distributed in the world's ocean, recent development of satellite-derived gravity data analysis provides us with enormous information about the seafloor. We analyze the distribution and the characteristics of the "superplume-origin" seafloor topography by using satellite data as well as ship depth soundings.

\section{Numerical Simulation}

Numerical simulation study of unsteady mantle convection may provide basic and fundamental understanding of the dynamics of superplumes within the Earth. Recently, we developed codes for two-dimensional and three-dimensional simulations of mantle convection. The newly developed simulation codes are based on the finite-volume method and incorporate temperature-dependent viscosity and phase changes. We refer to recent geophysical and geological results from seismic tomography and geochemistry to constrain the models. We describe several research plans related to the superplume activity: (1) Realistic physical and chemical modeling of the mantle layer, e.g., rheological parameters; (2) Effects of the initial and boundary conditions; (3) Effects of the structure of thermal boundary layers at the Earth's surface and the lowermost mantle (D" layer); (4) Comparison of two-dimensional and three-dimensional models; (5) Thermal energy transportation process; (6) How to incorporate the large-scale tectonics of the lithosphere, e.g., realistic modeling of subduction process and transform faults; (7) Thermomechanical interaction between plumes and spreading ridge systems; (8) Evolutionary process of hot and cold superplumes; (9) Dynamics within other planets such as Mars and Venus. In relation to (8) above, we study the effects of the continental lithosphere on mantle convection by simulation in a two-dimensional box with phase changes. The continental lithosphere is assumed to be more viscous than the other part (We call this area "oceanic lithosphere"). We found distinctly different modes of interaction of plumes with the transition zone under continental and oceanic lithospheres. That is, larger stationary plumes are developed under continents, and sometimes hot blobs emerge from the phase boundary. Weaker plumes are observed under the oceanic 
lithosphere. We also found, even in the presence of internal heat sources, the formation of large plumes under the continental lithosphere because of the depth dependent physical properties and the presence of continental lithosphere. This result has important implications for plume activity and continental break-up. Our numerical simulation studies may contribute to investigations of local and/or large-scale dynamics within the Earth as well as within the other planets such as Mars and Venus.

Acknowledgments. The authors would like to thank Hiroo Kanamori and Yoshiteru Kono for their valuable comments.

\section{References}

Crough, S. T., Hotspot swells, Ann. Rev. Earth Planet. Sci., 11, 165-193, 1983.

Defant, M. J. and M. S. Drummond, Derivation of some modern arc magmas by melting of young subducted lithosphere, Nature, 347, 662-665, 1990.

Geller, R. J. and T. Hara, Two efficient algorithms for iterative inversion of seismic waveform data, Geophys. J. Int., 115, 699-710, 1993.

Hirose, K., Y. Fei, Y. Ma, and H.-K. Mao, Fate of subducted basaltic crust in the lower mantle, Nature, 1998 (submitted).

Hofmann, A. W. and W. M. White, Mantle plumes from ancient oceanic crust, Earth Planet. Sci. Lett., 57, 421-436, 1982.

Inoue, H., Y. Fukao, K. Tanabe, and Y. Ogata, Whole mantle P-wave travel time tomography, Phys. Earth Planet. Inter., 59, 294-328, 1990.

Maruyama, S., Plume tectonics, J. Geol. Soc. Japan, 100, 24-49, 1994.

Maruyama, S., Pacific-type orogeny revisited: Miyashiro-type orogeny proposed, The Island Arc, 6, 91-120, 1997.

Maruyama, S., M. Kumazawa, and S. Kawakami, Towards a new paradigm on the Earth's dynamics, J. Geol. Soc. Japan, 100, 1-3, 1994.

McNutt, M. K. and K. Fischer, The South Pacific Superswell, in Seamounts, Islands, and Atolls, edited by B. H. Keating, P. Freyer, R. Batiza, and G. W. Boehlert, pp. 25-34, Geophys. Monogr., No. 43, AGU, Washington D.C., 1987.

Su, W., R. L. Woodward, and A. M. Dziewonski, Degree 12 model of shear velocity heterogeneity in the mantle, J. Geophys. Res., 99, 6945-6980, 1994

M. Ishida (e-mail: ishida@geo.bosai.go.jp), S. Maruyama (e-mail: smaruyam@geo.titech.ac.jp), D. Suetsugu (e-mail: dai@kenken.go.jp), S. Matsuzaka (e-mail: shigeru@gaos.gsi-mc.go.jp), and T. Eguchi (e-mail: eguchi@bosai.go.jp) 